\title{
Solar Evaporator with Controlled Salt Precipitation for Zero Liquid Discharge Desalination
}

\author{
Yusuf Shi, Chenlin Zhang, Renyuan Li, ${ }^{\circledR}$ Sifei Zhuo, Yong Jin, ${ }^{\circledR}$ Le Shi, Seunghyun Hong, ${ }^{\circledR}$ Jian Chang, \\ Chisiang Ong, and Peng Wang*(0)
}

Water Desalination and Reuse Center, Division of Biological and Environmental Science and Engineering, King Abdullah University of Science and Technology, Thuwal 23955-6900, Saudi Arabia

Supporting Information

\begin{abstract}
A sustainable supply of clean water is essential for the development of modern society, which has become increasingly dependent on desalination technology since 96.5\% of the water on Earth is salt water. Thousands of desalination plants are producing massive waste brine as byproduct, and the direct discharge of brine raises serious concerns about its ecological impact. The concept of zero liquid discharge (ZLD) desalination is regarded as the solution, but the current ZLD technologies are hampered by their intensive use of energy and high cost. In this work, a 3D cup shaped solar evaporator was fabricated to achieve ZLD desalination with high energy efficiency via solar distillation. It produces solid salt as the only byproduct and uses sunlight as

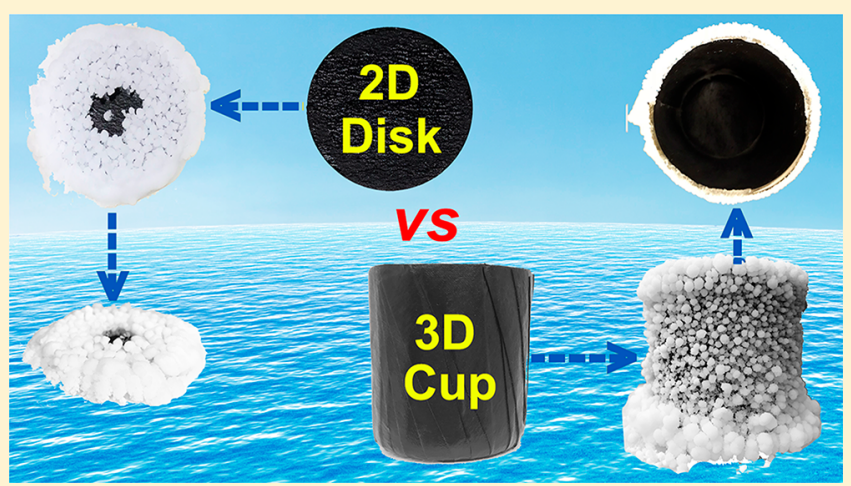
the only energy source. By rationally separating the light absorbing surface from the salt precipitation surface, the light absorption of the $3 \mathrm{D}$ solar evaporator is no longer affected by the salt crust layer as in conventional 2D solar evaporators. Therefore, it can be operated at an extremely high salt concentration of 25 wt \% without noticeable water evaporation rate decay in at least $120 \mathrm{~h}$. This new solar evaporator design concept offers a promising technology especially for high salinity brine treatment in desalination plants to achieve greener ZLD desalination as well as for hypersaline industrial wastewater treatment.
\end{abstract}

\section{INTRODUCTION}

The total installed capacity of near 20000 desalination plants around the world is over 85 million tons per day ${ }^{1,2}$ and is projected to keep growing rapidly in the coming decades due to population growth, steadily improved life standards, and lack of fresh water resources. ${ }^{3,4}$ These desalination plants produce a large amount of waste brine as byproduct. Currently, most of the waste brine from desalination plants is discharged directly into municipal sewers, groundwater, coastal waters, and open land evaporation ponds. ${ }^{5-8}$ Moreover, many industrial processes also produce a large amount of waste brine that needs to be treated before disposal. ${ }^{9,10}$ Recently, it is reported that the directly disposal of waste brine has proven detrimental effects on aquatic ecosystems and land vegetation systems. $^{11-14}$ In light of ever-tightening environmental regulations and the fast growing waste brine production, brine disposal will face great challenges in the very near future. ${ }^{2}$

The concept of zero liquid discharge (ZLD) desalination is regarded as the solution to the brine disposal issue as it produces only solid salts byproduct and clean water from source water. ${ }^{10}$ However, the main desalination technologies in the current market, such as reverse osmosis (RO), multistage flash distillation (MSF), and multiple-effect distillation (MED), are all infeasible to directly achieve ZLD desalination by their own because of their respective technology limitations or unacceptably high costs. ${ }^{10} \mathrm{~A}$ more practical strategy adopted by the current industry is combining a ZLD brine treatment system with those conventional desalination technologies to treat the brine byproducts. ${ }^{15-17}$ The current ZLD brine treatment systems are mainly composed of a brine concentration system followed by a brine crystallizer or an evaporation pond. ${ }^{10}$ High pressure RO, cascading osmotically mediated RO, forward osmosis, MSF, and other technologies have been investigated for brine concentration, while the brine crystallizers have rarely improved in the past several decades. ${ }^{10,18}$ These ZLD systems have been in operation for more than 40 years but only with very limited installed capacity due to extremely high energy consumption and capital/ operation costs. ${ }^{10}$

Recently, advanced solar distillation has attracted a great deal of interest in clean water production, because it does not need any mechanically moving parts, it does not entail high pressure or vacuum operation, and it uses sunlight as the only

Received: June 18, 2018

Revised: September 12, 2018

Accepted: September 17, 2018

Published: September 17, 2018 
energy source. ${ }^{19,20}$ All these features make it a promising desalination technology with minimum environmental impact and great advantages in both capital and operation costs. ${ }^{20}$ In a typical solar distillation apparatus, solar evaporator is the key component, which captures sunlight, converts it to heat, and thereafter drives water evaporation from all kinds of source water. Various photothermal materials with extremely high light absorption and diverse heat management strategies have been developed to fabricate an advanced solar evaporator in the last four years, ${ }^{21-32}$ leading to the state of the art solar-towater-evaporation efficiency being $>90 \% .{ }^{33-42}$ However, in the case of salt water being adopted as source water in solar distillation, the salt accumulation on solar evaporator causes a serious concern because it may significantly affect the performance during long-term operation. Recently, it was reported that when a conventional $2 \mathrm{D}$ solar evaporator made of reduced graphene oxide ( $\mathrm{rGO}$ ) membrane was operated at a higher concentrated brine, e.g. $15 \mathrm{wt} \%$, a thick white salt crust formed on top of the membrane in several hours and blocked the sunlight, leading to a small water evaporation rate $(\sim 0.5 \mathrm{~kg}$ $\left.\mathrm{m}^{-2} \mathrm{~h}^{-1}\right){ }^{43}$ Very recently, it has been reported that if some special designed solar evaporators are directly floating on seawater with $3.5 \mathrm{wt} \%$ salt concentration, the salt can dissolve back to the seawater without a salt accumulation problem. ${ }^{44-46}$ However, it is equivalent to directly discharge salt back into the sea, and therefore the environmental impact issues still exist for these solar stills.

In this work, a cup shaped photothermal structure was fabricated as a $3 \mathrm{D}$ solar evaporator from a silica/carbon/silica (SCS) trilayered coaxial fibrous membrane, which possesses a high light absorption of $99.35 \%$ and a nearly $100 \%$ efficiency in solar evaporation. It can be directly applied to extremely high concentration brines ( $25 \mathrm{wt} \%$ ) with only a slight decrease in the water evaporation rate compared to that for pure water. More importantly, in this 3D solar evaporator, the light absorbing surface and salt precipitation surface are rationally separated, and it thus wisely solves the salt accumulation issue, making it able to treat near saturated $\mathrm{NaCl}$ brine ( $25 \mathrm{wt} \%$ ) with a high and stable water evaporation rate of $1.26 \mathrm{~kg} \mathrm{~m}^{-2}$ $\mathrm{h}^{-1}$ even after $120 \mathrm{~h}$ operation. More solar evaporator devices can be further designed under the guidance of separating the salt precipitation surface from the light absorbing surface. We believe the stable and high efficient water removal on the 3D solar evaporator is a promising brine treatment technology for desalination plants to realize ZLD by combining this technology with the conventional desalination processes.

\section{RESULTS AND DISCUSSION}

Synthesis and Characterization of 2D and 3D SCS Materials. The SCS material with a coaxial trilayered fibrous membrane structure was synthesized by using a quartz glass fibrous (QGF) membrane as a matrix material, phenol formaldehyde resins (PF) as a carbon precursor, and tetraethyl orthosilicate (TEOS) as a precursor of the outer silica layer (Figure 1). The pristine QGF membrane with a nonwoven structure is made of quartz glass fibers with diameters ranging from $200 \mathrm{~nm}$ to more than $2 \mu \mathrm{m}$ without any binder (Figure $2 \mathrm{a}$ and $\mathrm{b}$ ). An ultrathin PF layer and an additional silica layer were successively coated onto the quartz glass fibers by a dip coating method (Figure S2). The intermediate silica/PF/silica coaxial fibrous membrane was then converted to the silica/ carbon/silica coaxial fibrous membrane by calcination in a tube furnace in inert atmosphere (Figure $2 \mathrm{c}$ and $\mathrm{d}$ ).

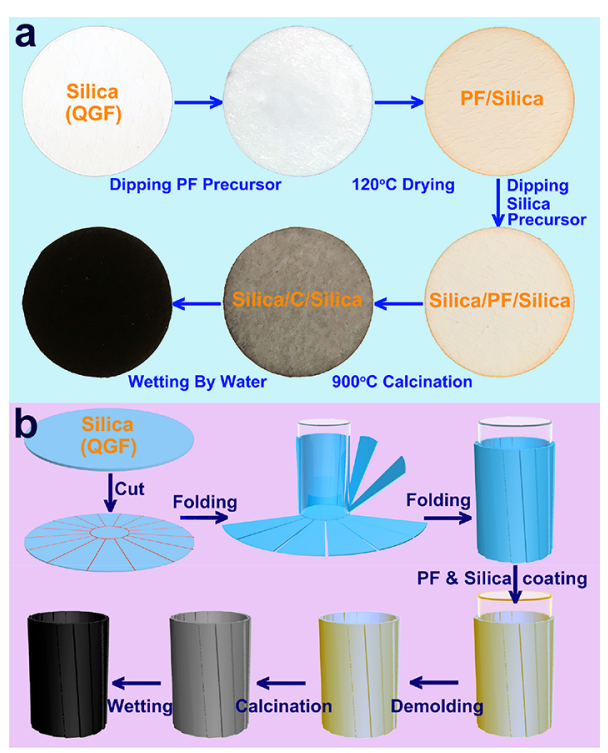

Figure 1. (a) Photo images of the QGF matrix membrane, the SCS membrane, and its intermediate products. The gray SCS membrane turns to deep dark when wetted by water. (b) Scheme of the fabrication process for the 3D SCS cup structure by using a glass cup as mold.

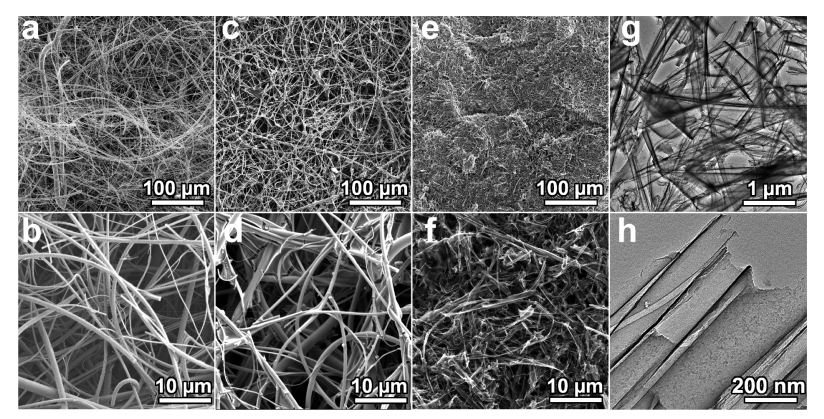

Figure 2. SEM images of $(a, b)$ the pristine QGF membrane and (c, d) the SCS composite product. The (e, f) SEM and (g, h) TEM images of the residual carbon tubes from the SCS composite after the removal of silica by HF.

TGA analysis indicates that the carbon content in the final SCS composite is $\sim 1.2$ wt \% (Figure S3). The presence of amorphous carbon in the SCS membrane is also confirmed by Raman spectrum and XRD analyses (Figures S4 and S5). The smooth tubelike structure of the carbon layer (Figure 2e-h), investigated by SEM and TEM after all silica was etched away by $\mathrm{HF}$, is clear evidence for the uniform PF coating and its subsequent successful conversion to carbon in the synthesis.

The SCS sample possesses a gray color in the dry state (Figure 1) with an average reflectance of $14.2 \%$ (Figure 3a, Figure S6). The high reflectance is caused by the strong subsurface scattering at the air/solid interface inside the highly porous structure. ${ }^{47}$ Fortunately, the wet SCS sample turns a deep black color (Figure 1) with a much smaller average reflectance of $3.40 \%$ (Figure $3 a$ ), as the subsurface scattering is greatly diminished once the solid/air interfaces inside the membrane are replaced by solid/water interfaces in the wet state. ${ }^{48,49}$ It has been reported that by making the $3 \mathrm{D}$ structure to create multiple internal reflection of the incident light, extremely low reflectance can be achieved. ${ }^{33,34,50}$ In this work, a $3 \mathrm{D}$ cup shaped SCS structure was fabricated as schemed in 

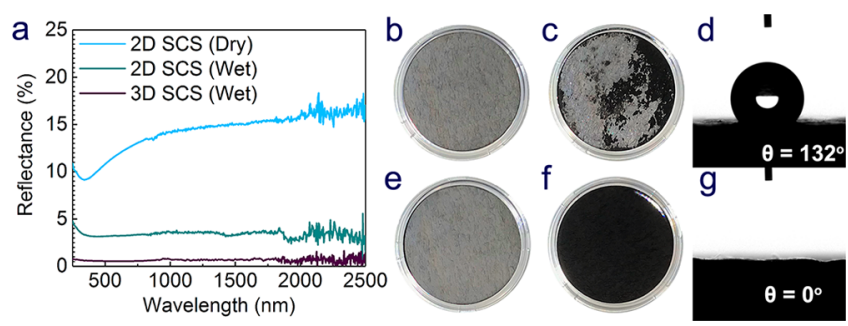

Figure 3. (a) The UV-vis-NIR spectra of the 2D SCS disk and the 3D SCS cup in dry and wet states. The photo images of a bilayer silica/ carbon disk (b) in air and (c) under water and a trilayer silica/ carbon/silica (SCS) disk (e) in air and (f) under water. The corresponding static contact angles $(\theta)$ of $4-\mu \mathrm{L}$ sessile droplets on (d) a bilayer silica/carbon disk and (g) a trilayer silica/carbon/silica disk.

Figure $1 \mathrm{~b}$. Its light reflectance significantly decreased to $0.65 \%$ (Figure 3a, Figure S6), which is only $19 \%$ of that of the wet 2D SCS material (3.40\%). This result suggests that more than $80 \%$ of the reflected light by the $2 \mathrm{D}$ bottom of the $3 \mathrm{D}$ cup is recovered by its wall. ${ }^{34}$

The major reason for coating an additional silica layer on top of the carbon layer is to adjust the wettability. Without the outer silica layer, the composite material is hydrophobic with a contact angle of $132^{\circ}$ in most parts (Figure 3d). Therefore, only a few water-wettable domains turn from gray to dark black color when it is immersed underwater (Figure 3c). With the additional silica layer, the entire material is superhydrophilic with a contact angle of $0^{\circ}$ (Figure $3 \mathrm{~g}$ ) and a water spreading time of less than $0.04 \mathrm{~s}$ (Figure S8). In this case, the gray dry sample immediately turns dark black when wetted with water (Figure 3f). The hydrophilicity of the membrane is essential to ensure that it can automatically draw source water via capillary effects. In addition, the outer silica layer also acts as an antireflection layer, because it possesses a moderate reflective index $(1.48-1.56)$ in the solar spectrum range, ${ }^{51}$ which is higher than water $(1.31-1.34)^{52}$ but lower than amorphous carbon $(2.1-2.4),{ }^{53}$ and therefore it decreases the reflectance of the membrane (Figure S9). ${ }^{54}$
Solar Driven Brine Water Evaporation. The evaporation rates of pure water and saltwater with different $\mathrm{NaCl}$ concentrations on $2 \mathrm{D}$ and $3 \mathrm{D}$ solar evaporators were measured in a lab-made setup as illustrated in Figure 4a. The projected area is used for specific evaporation rate calculation, because it is directly proportional to the input energy from the simulated sunlight beam. An expanded polystyrene (EPS) foam with thermal conductivity of $\sim 0.03 \mathrm{~W} \mathrm{~m}^{-1} \mathrm{k}^{-1}$ was used as a thermal insulation part under the solar evaporator to diminish the heat loss. The source water is transported to the center of the bottom of the solar evaporator by a QGF strip through a hole in the EPS foam (Figure 4a), and then it automatically spreads over the entire solar evaporator via capillary effect. The concentration of the source water (wt \%) is defined as the weight of $\mathrm{NaCl}$ solute per unit weight of solution in this work.

The evaporation rate of pure water on a 2D SCS disk under one sun illumination was $1.25 \mathrm{~kg} \mathrm{~m}^{-2} \mathrm{~h}^{-1}$ (Figure 4d), corresponding to an energy efficiency of $79 \%$. As the pure water was replaced with saltwater, the evaporation rate gradually decreased to $1.20,1.16,1.12$, and $1.06 \mathrm{~kg} \mathrm{~m}^{-2} \mathrm{~h}^{-1}$ when the concentration was increased to $10,15,20$, and $25 \mathrm{wt}$ $\%$, respectively (Figure $4 \mathrm{~b}$ and $\mathrm{d}$ ). At a certain temperature, the vapor pressure of $\mathrm{NaCl}$ aqueous solution with 25 wt \% concentration is $\sim 23 \%$ lower than that of pure water (Figure 4d). ${ }^{55}$ Nevertheless, the evaporation rate of $25 \mathrm{wt} \%$ saltwater is only $\sim 15 \%$ lower than that of pure water (Figure $4 \mathrm{~d}$ ). This is because the equilibrium temperature of the water/air interface increases to a higher value when the evaporation rate is lowered down at high salt concentration (Figure 4e). The surface temperature was $40{ }^{\circ} \mathrm{C}$ when the source water is pure water (Figure $4 \mathrm{~g}$ ), and it increased to 43 and $47{ }^{\circ} \mathrm{C}$ when the source water was replaced with 15 and 25 wt \% brine (Figure $4 i$ and $k$ ). The higher equilibrium temperature increases the water vapor pressure, which in turn partially compensates the vapor pressure decrease caused by colligative properties and ultimately leads to less reduced water evaporation rates with the salt water (Figure 4d).

When a 3D cup structure of SCS material with a diameter of $5.5 \mathrm{~cm}$ and a height of $8.0 \mathrm{~cm}$ was used as solar evaporator, the
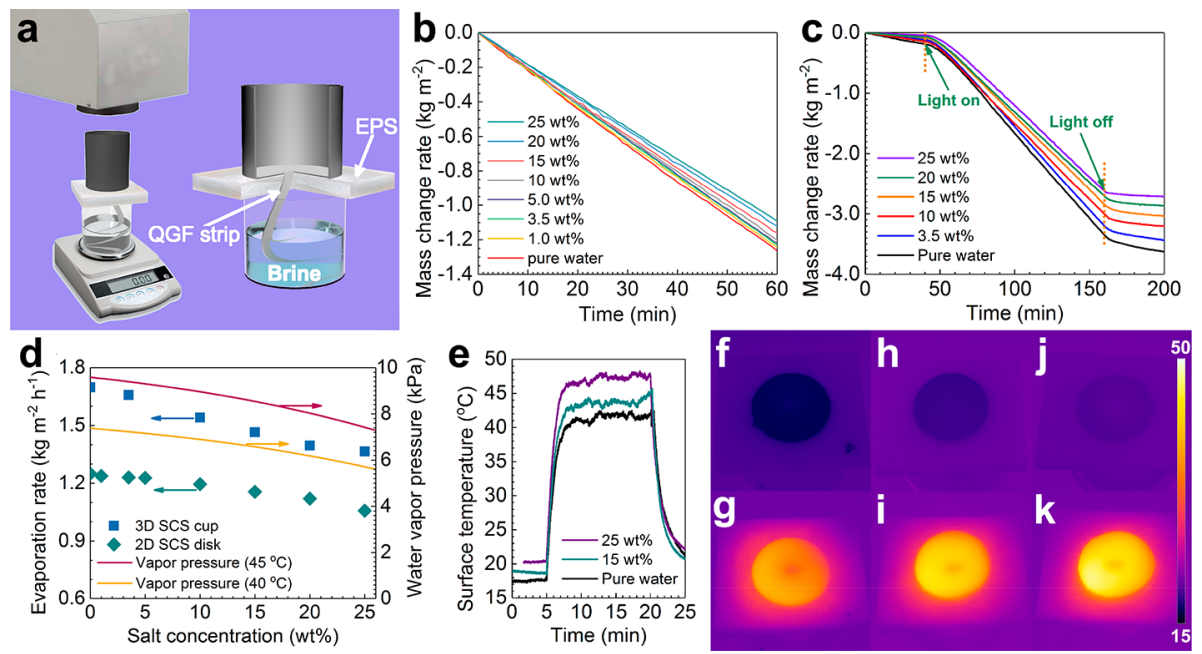

Figure 4. (a) The scheme of the lab-made solar evaporation performance measurement system. The mass change curves of $\mathrm{NaCl}$ aqueous solution with different concentrations when (b) a 2D SCS disk and (c) a 3D SCS cup is used as the solar evaporator under one sun illumination and (d) the corresponding water evaporation rates. (e) The surface temperature change curves of a 2D SCS disk when the source water is pure water, and $\mathrm{NaCl}$ aqueous solution with 15 and 25 wt \% concentration. The IR image of a 2D SCS disk (f, h, j) in the dark and (g, i, k) under simulated sunlight when it was wetted by (f, g) pure water, $(h, i) 15$ wt \% brine, and $(j, k) 25$ wt \% brine. 

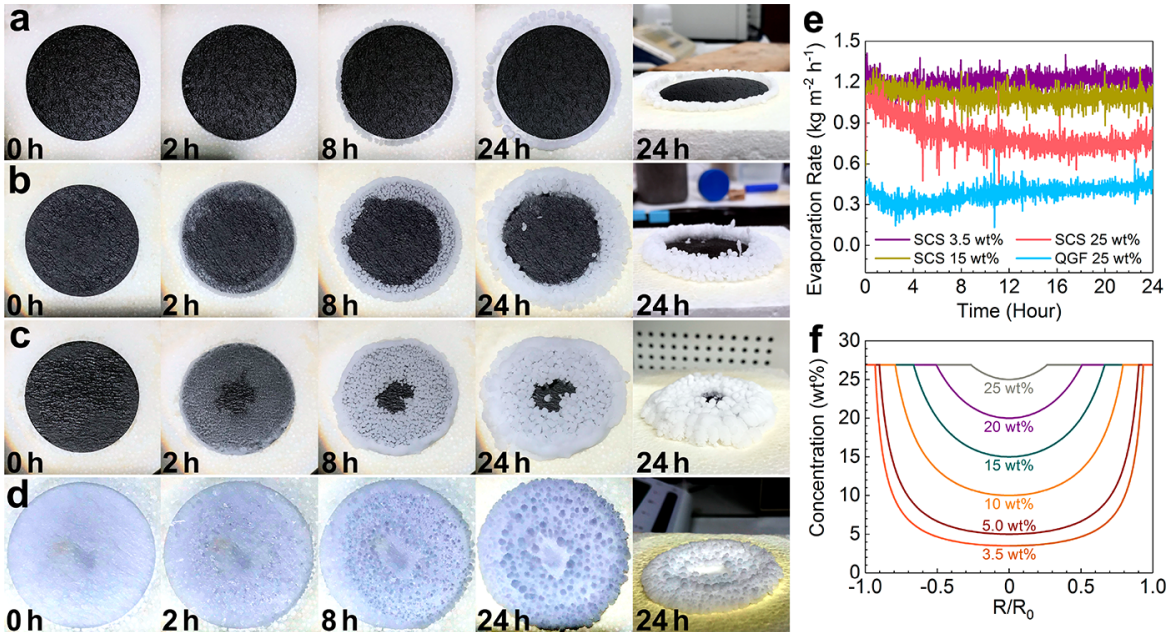

Figure 5. Salt precipitation images of (a, b, c) 2D SCS disks and (d) a 2D QGF disk using salt water with (a) 3.5 wt \%, (b) 15 wt \%, and (c, d) 25 wt $\%$ concentration as source water and (e) the corresponding water evaporation rate curves. (f) The theoretical radial salt concentration profiles when $\mathrm{NaCl}$ aqueous solution with different concentrations are used as source water on a round shape $2 \mathrm{D}$ solar evaporator. (Note: Images in (d) are colored to increase contrast; the original images can be found in Figure S10; (f) $R_{0}$ is the radius of the 2D SCS disk, and R is the distance between the position of interest and the center of the circular disk.)

evaporation rate of pure water was significantly increased to $1.70 \mathrm{~kg} \mathrm{~m}^{-2} \mathrm{~h}^{-1}$ (Figure $4 \mathrm{c}$ and $\mathrm{d}$ ), corresponding to an energy efficiency of $96.7 \%$. The extremely high energy efficiency is because the wall of the cup structure can efficiently recover most of the energy loss from the $2 \mathrm{D}$ bottom disk, including the reflectance loss, thermal radiation, and convection heat loss as discussed in the literature. ${ }^{33-35}$ Since a small part of the EPS foam is also exposed under simulated sunlight, the diffuse reflection light from the EPS foam may also slightly contribute to it $(<3 \%)$. The average water evaporation rate in the first $2 \mathrm{~h}$ of the $3 \mathrm{D}$ solar evaporator decreased to $1.36 \mathrm{~kg} \mathrm{~m}^{-2} \mathrm{~h}^{-1}$ when the salt concentration was increased to $25 \mathrm{wt} \%$, corresponding to an energy efficiency of $88.4 \%$, only slightly lower than that for pure water.

These results demonstrate that the water evaporation rate of highly concentrated brine is only slightly lower than that of pure water in a solar-driven water evaporation process, and no operation condition change is necessary for difference source waters. For a conventional RO process, the operation pressure is significantly dependent on the salinity of the source water (Figure S1a). ${ }^{56}$ Recently, a cascading osmotically mediated reverse osmosis technology has been reported to decrease the operation pressure, but it increases the complexity of the system. ${ }^{18}$ A loosened requirement for operating conditions and system configuration in treating a highly concentrated source brine can be regarded as a great advantage of this method, which translates into significantly reduced investment cost.

Salt Precipitation on 2D Disk Shaped SCS Solar Evaporator. Figure 5a-c lists the images of salt crystals formed on a 2D SCS disk after being exposed under one sun illumination for $0,2,8$, and $24 \mathrm{~h}$ with $3.5,15$, and 25 wt $\%$ brines as source waters. When the concentration is $3.5 \mathrm{wt} \%$, the salt precipitation only occurred at the far edge part after 2 h. Very interestingly, the salt crystal slowly migrated out of the SCS disk after 8 and $24 \mathrm{~h}$ (Figure 5a). As a result, the light absorption ability of the $2 \mathrm{D}$ disk was not affected by the salt precipitation in this case, and consequently the water evaporation rate kept steady in $24 \mathrm{~h}$ without noticeable decrease $\left(\sim 1.24 \mathrm{~kg} \mathrm{~m}^{-2} \mathrm{~h}^{-1}\right)$ (Figure $5 \mathrm{e}$ ).
When the source water concentration is $15 \mathrm{wt} \%$, the salt precipitated on the edge parts forming a clearly ring shape (Figure $5 \mathrm{~b}$ ). Approximately $50 \%$ of the surface was covered by the precipitated salt, and therefore the light absorption was inevitably affected by the salt crust as the thickness of the salt crust kept growing. As a result, the water evaporation rate decreased from 1.16 to $1.09 \mathrm{~kg} \mathrm{~m}^{-2} \mathrm{~h}^{-1}$ in the first $8 \mathrm{~h}$ and kept stable thereinafter for the next $16 \mathrm{~h}$. With the concentration of the source brine being $25 \mathrm{wt} \%$, which is close to a fully saturated solution, the salt crust almost fully covered the entire disk except a small hole in the center (Figure 5c). Since only less than $10 \%$ surface was left uncovered, the water evaporation rate was significantly decreased from $1.06 \mathrm{~kg} \mathrm{~m}^{-2} \mathrm{~h}^{-1}$ to 0.73 $\mathrm{kg} \mathrm{m}^{-2} \mathrm{~h}^{-1}$ in $16 \mathrm{~h}$, equivalent to a $31 \%$ decrease.

If a QGF disk without carbon was used as a solar evaporator, the water inside the membrane acts as the photothermal component since it strongly absorbs near IR light in the solar spectrum. ${ }^{57}$ The initial evaporation rate was $0.40 \mathrm{~kg} \mathrm{~m}^{-2} \mathrm{~h}^{-1}$, and it quickly decreased to $0.30 \mathrm{~kg} \mathrm{~m}^{-2} \mathrm{~h}^{-1}$ in $3 \mathrm{~h}$. Interestingly, the evaporation increased in the next $21 \mathrm{~h}$ and ended with a rate of $0.45 \mathrm{~kg} \mathrm{~m}^{-2} \mathrm{~h}^{-1}$. The increased evaporation rate can be attributed to the enlargement of the salt crust, which increased both the light absorbing area and water evaporation area from $17.3 \mathrm{~cm}^{2}$ to $23.1 \mathrm{~cm}^{2}$ in $24 \mathrm{~h}$. If this surface area enlargement is taken into account, the evaporation rate is adjusted to only $0.34 \mathrm{~kg} \mathrm{~m}^{-2} \mathrm{~h}^{-1}$ at $24 \mathrm{~h}$. It should be mentioned that the salt crust enlargement during operation also happens in 2D SCS disks. When 25 wt \% brine is used as the source water, the evaporation rate at $24 \mathrm{~h}$ is listed as $0.73 \mathrm{~kg} \mathrm{~m}^{-2} \mathrm{~h}^{-1}$ in Figure 5e. However, if the salt crust enlargement effect is factored in, the adjusted evaporation rate is only $0.51 \mathrm{~kg} \mathrm{~m}^{-2} \mathrm{~h}^{-1}$, which is less than half of the initial evaporation rate. To sum up, for a $2 \mathrm{D}$ solar evaporator, the entire disk surface acts both as a sunlight absorbing surface and a water evaporation interface. When part of its surface is covered by the white salt crust, the light absorbing efficiency is undesirably decreased, leading to its decreased evaporation rate as described above, and thus making it not suitable for longterm brine treatment. 


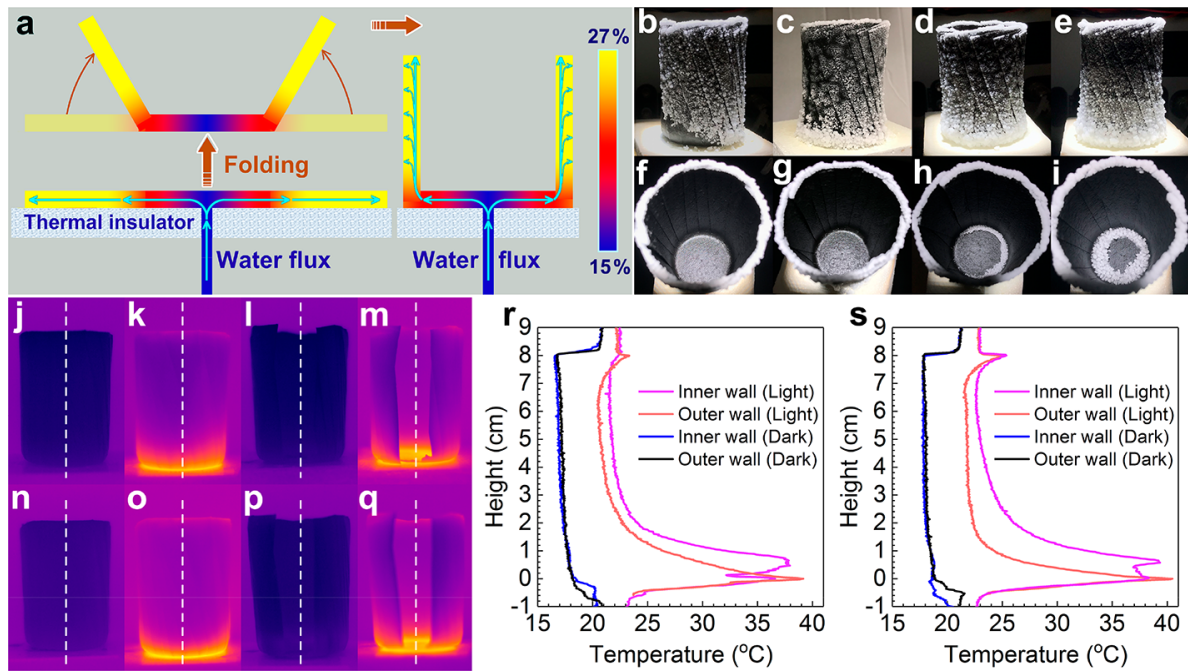

Figure 6. (a) The scheme of the design concept for the 3D cup structured solar evaporator. Images of salt precipitation on a 3D cup solar evaporator when it was operated at (b, f) $10 \mathrm{wt} \%,(\mathrm{c}, \mathrm{g}) 15 \mathrm{wt} \%,(\mathrm{~d}, \mathrm{~h}) 20 \mathrm{wt} \%$, and $(\mathrm{e}, \mathrm{i}) 25 \mathrm{wt} \% \mathrm{NaCl}$ brine under one sun illumination after 24 $h$. The IR images of the wet $3 \mathrm{D}$ cup structure $(j, 1, n, p)$ in the dark and $(k, m, o, q)$ under light when wetted by $(j, k, l, m)$ pure water and $(n, o, p$, q) $15 \mathrm{wt} \%$ brine. The corresponding temperature profiles that were read from the white light lines in the IR images are presented in ( $r$ ) for the pure water case and (s) for the 15 wt \% brine case.

However, our attention was attracted by the fact that the salt crust always left some central areas uncovered (Figure 5b and c). In this work, the source water is supplied to the central part of the disk by the hydrophilic QGF strip and then spreads out to the edges along the radial directions. Along any radial direction outward, the salt concentration gradually increases due to the continuous water removal via evaporation. The $\mathrm{NaCl}$ crystal only grows and precipitates out after the salt concentration reaches the saturation concentration of $\mathrm{NaCl}$. We calculated the radial salt concentration profiles for different salty source water using a simplified model (see the Supporting Information), and the results are presented in Figure $5 f$, in which $R_{0}$ is the radius of the SCS disk, and $R$ is the distance between the position of interest and the center of the circular disk. The salt concentration right at the center of the disk is equal to the source water, and it gradually increases with the increase of $R / R_{0}$ along the radial direction (Figure $5 f$ ). The salt solution would reach its saturation state at a critical point beyond which the concentration remains the same as the higher limit of the saturated solution (i.e., $\sim 26.9$ wt \% at $40-$ $50^{\circ} \mathrm{C}$ for $\mathrm{NaCl}$ ). In this stage, other than a concentration increase, the water removal is accompanied by the formation of salt precipitation. Consequently, the salt crystal only grows and covers on this edge region beyond the critical $R / R_{0}$ and forms a salt crust with a ring shape (Figure 5a-c, f).

Our calculations show that when the source water is $3.5 \mathrm{wt}$ $\% \mathrm{NaCl}$ aqueous solution, the $\mathrm{NaCl}$ only precipitates on the far edge part with a critical $R / R_{0}>0.95$. When the salt concentration increases to 15 and 25 wt $\%$, the critical $R / R_{0}$ decreases to 0.72 and 0.31 , respectively. All these calculated $R /$ $R_{0}$ values are quite close to those observed experimentally (Figure S19, 5a-c). Thus, based on the experimental results and calculations, the inner diameter of the salt crust ring depends on the concentration of the source water, but it is independent of the absolute evaporation rate. In other words, the salt precipitation zone is delineated by the salt concentration in source water and does not shift with the change of the evaporation rate either caused by fluctuation of sunlight intensity, wind speed, or by the change of ambient humidity. It has been reported that these factors all greatly affect the evaporation rate of water. ${ }^{58}$ Our results do show that when a white and pristine QGF without carbon was used as a solar evaporator and a brine with $25 \mathrm{wt} \% \mathrm{NaCl}$ concentration as source water, a salt crust was obtained (Figure $5 \mathrm{~d}$ ) similar to that of a 2D SCS disk under otherwise the same conditions (Figure 5c), although the QGF disk exhibited a much lower evaporation rate $\left(0.46-0.30 \mathrm{~kg} \mathrm{~m}^{-2} \mathrm{~h}^{-1}\right)$ than that of the SCS disk (1.06-0.73 $\mathrm{kg} \mathrm{m}^{-2} \mathrm{~h}^{-1}$ ) (Figure 5e).

It should be noted that before the water evaporation takes place, the initial salt concentration of the entire solar evaporator is uniformly equal to the source brine. The concentration distribution profiles gradually change in the first several hours of the water evaporation. Before achieving the equilibrium state, the salt concentration within the entire evaporator keeps increasing, leading to a decrease in the water evaporation rate in the first several hours in all experiments.

Salt Precipitation on 3D Cup Shaped SCS Solar Evaporator and Its Control Strategy. For a 2D disk solar evaporator, the salt precipitation takes place on the edge part beyond a critical $R / R_{0}$ as illustrated as the yellow zone in Figure 6a. We hypothesize that, if the $2 \mathrm{D}$ disk is folded into a $3 \mathrm{D}$ cup structure with the yellow zone present only in the wall part of the structure (Figure 6a), the salt precipitation would then occur only on the wall part of the 3D cup, making the bottom light absorbing part no longer affected by the salt crust formation. Under this design, the 3D cup structure would judiciously separate its light absorbing surface from its salt precipitation surface physically, and thus the light absorption would not be affected by precipitated salt anymore, which is otherwise the Achilles heel of the $2 \mathrm{D}$ solar evaporator and makes it unsuitable for stable brine treatment.

A 3D cup shaped SCS structure with a diameter of $5.5 \mathrm{~cm}$ and a height of $8 \mathrm{~cm}$ was fabricated (Figure $1 \mathrm{~b}$ and S11) and used as solar evaporator to investigate its brine treatment performance. After $24 \mathrm{~h}$ exposure under one sun illumination, the outer wall of the cup was covered with salt crystals in each of the experiments as shown in Figure $6 \mathrm{~b}$-e. The $\mathrm{NaCl}$ crust on the outer wall was composed of loosely packed salt balls with 

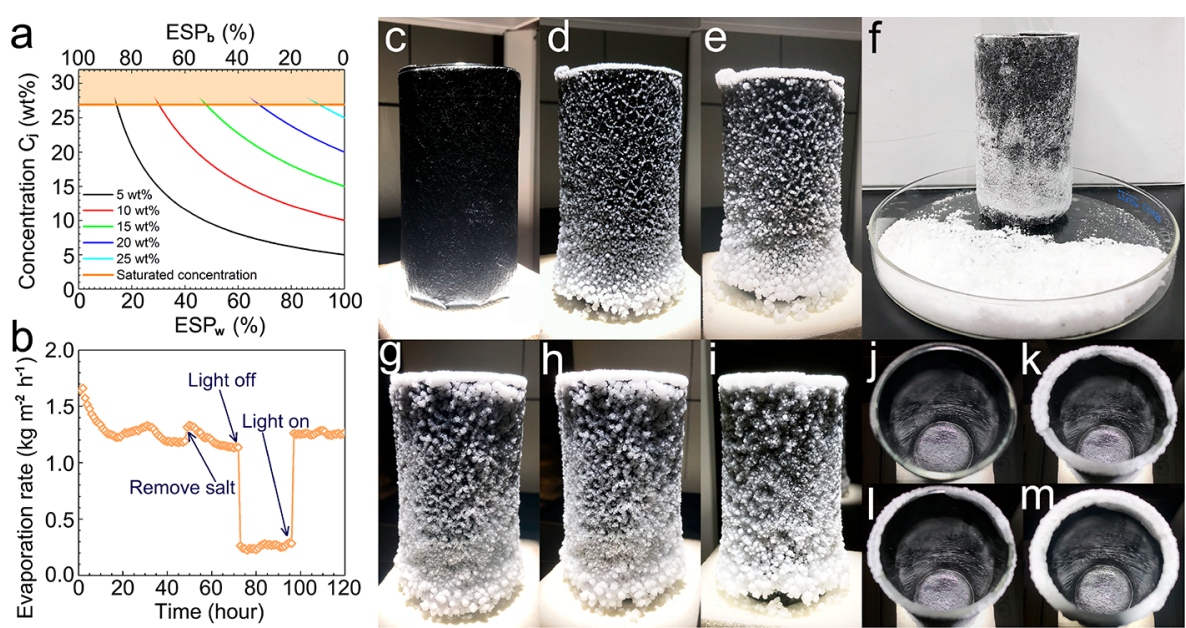

Figure 7. (a) The calculated salt concentration at the bottom-wall junction part $\left(C_{j}\right)$ of $3 \mathrm{D}$ cup shaped solar evaporators with different ESP $\mathrm{w}_{w}$ using the brines with different concentrations as source water. (b) The water evaporation rate of a 3D cup shaped solar evaporator with a glass cup inside it for long-term brine treatment. The corresponding images of the solar evaporator at different times: (c, j) 0 h, (d) 24 h, (e, k) 48 h, (f) 48 h after salt removal, (g, l) 72 h, (h) 96 h, (i, m) 120 h.

plenty of void inside the salt layer (Figure S12). When the concentration of the source water was 20 and 25 wt \%, some salt crystal still formed and precipitated on the bottom part (Figure $6 \mathrm{~h}$ and i, Figure S13). However, when brines with 10 or $15 \mathrm{wt} \% \mathrm{NaCl}$ concentration were used as source water, very excitingly, no $\mathrm{NaCl}$ crystal precipitation was observed on the inside bottom part of the cup at least during the $24 \mathrm{~h}$ test (Figure $6 \mathrm{f}$ and $\mathrm{g}$ and Figure S13). This result indicates the expectation of separating the salt precipitation surface from the light absorbing surface can be achieved by this 3D solar evaporator, at least in the case of brines with concentrations lower than 15 wt \%. We operated such a 3D solar evaporator for $72 \mathrm{~h}$ using $15 \mathrm{wt} \%$ brine as source water, and no evaporation rate decline was observed during the whole operation (Figure S15). These results demonstrate that the 3D solar evaporator can be utilized for continuous ZLD brine treatment, as long as the concentration of the source water is lower than 15 wt \%, which is a realistic condition since the concentration of the brines from $\mathrm{RO}$ desalination plants is generally lower than $15 \mathrm{wt} \%$.

One interesting observation is that even though salt crystal growth and precipitation was very significant (Figure $6 \mathrm{~b}-\mathrm{i}$ ) on the outer cup wall in all cases, the inner cup wall was always clean and uncovered by any salt (Figure 6i). The reasons are 2fold: (1) the humidity of the air outside the cup is $\sim 55 \%$, while the humidity inside the cup structure is nearly $100 \%$, which leads to a much faster water evaporation rate on the outer surface of the wall. Consequently, the salt concentration in the outer wall surface is higher than that in the inner wall surface. (2) Based on IR images, the temperature of the inner cup wall surface is higher than that of the outer surface (Figure 6j-q) both with the pure water case (Figure 6r) and the brine case (Figure 6s). The higher temperature of the inner cup wall would give rise to a higher $\mathrm{NaCl}$ solubility in the inner surface than in the outer surface. The above two factors combined together make the salt crystals tend to grow on the outer surface of the cup wall. The always clean inner cup wall is an unexpected result but would benefit stable brine treatment by the $3 \mathrm{D}$ cup solar evaporator. First, the inner wall acts as the energy recovery component by reabsorbing the diffuse reflected lights from the bottom part. ${ }^{34}$ Second, if salt crust were formed in the inner wall, some of them would drop onto the cup bottom during operation and thereafter affect the light absorption, since the salt crusts are quite loosely compacted. The drop of salt balls from the outer wall was indeed frequently observed in all experiments as shown in Figure S15.

The above results demonstrate that the salt precipitation zone can be successfully controlled only on the outer wall part when the concentration of the source water is lower than $15 \mathrm{wt}$ $\%$, but it failed in cases of brines with concentrations of 20 and 25 wt \% (Figure 6). The exact water evaporation rates of the cup bottom, the inner wall, and the outer wall are unknown for this 3D solar evaporator. Therefore, we are unable to provide a detailed concentration distribution profile for the $3 \mathrm{D}$ cup as that for 2D SCS disk. Instead we introduce an evaporation share percentage (ESP) value as a parameter to facilitate the analysis. ESP represents the percentage of the water vapor that is contributed from the bottom part $\left(\mathrm{ESP}_{\mathrm{b}}\right)$ and wall part $\left(\mathrm{ESP}_{\mathrm{w}}=100 \%-\mathrm{ESP}_{\mathrm{b}}\right)$. Theoretically, the $\mathrm{ESP}_{\mathrm{w}}$ can be tuned by the height of the wall, in which a higher wall leads to a higher $\mathrm{ESP}_{\mathrm{w}}$. The concentration at the bottom-wall junction part $\left(C_{j}\right)$ is calculated for a $3 \mathrm{D}$ evaporator with different $\mathrm{ESP}_{\mathrm{b}}$ when it is operated at different brine concentrations (see the Supporting Information), and the results are presented in Figure $7 \mathrm{a}$.

In a hypothetical situation, the structure with an extremely high wall will give a near $100 \% \mathrm{ESP}_{w}$, and in this case, the $C_{j}$ equals the concentration of the source water (Figure $7 \mathrm{a}$ ), because almost no water is removed before the flux leaves the bottom part. When the $\mathrm{ESP}_{\mathrm{w}}$ decreases, the $\mathrm{ESP}_{\mathrm{b}}$ increases, which means a greater portion of water is removed by water evaporation on the bottom part, leading to an increase of $C_{j}$. When the $\operatorname{ESP}_{\mathrm{w}}$ value lowers down to a critical value $\left(\operatorname{ESP}_{\mathrm{w}}{ }^{*}\right)$, $C_{\mathrm{j}}$ increases to the saturation concentration of $\mathrm{NaCl}$ (26.9 wt $\%)$, which means the flux is saturated in the junction part but still no salt precipitation occurs on the bottom part. Beyond this critical value, $C_{j}$ no longer decreases with a further decrease of $\mathrm{ESP}_{\mathrm{w}}$ but keeps at saturation concentration (Figure $7 \mathrm{a})$, and at this stage, salt crystal will precipitate on the bottom part.

Our calculation indicates that when the concentration of the source water is increased from $5 \mathrm{wt} \%$ to $10,15,20$, and $25 \mathrm{wt}$ 
$\%$, the critical $\mathrm{ESP}_{\mathrm{w}}{ }^{*}$ increases from $14 \%$ to $30 \%, 48 \%, 68 \%$, and $91 \%$, respectively (Figure $7 \mathrm{a}$ ). It suggests that for brines with concentration lower than 15 wt \%, as long as the $\mathrm{ESP}_{\mathrm{w}}$ is higher than $48 \%$, a reasonable value, $C_{j}$ is lower than the saturation concentration. Namely, if more than $48 \%$ of the water evaporation is contributed by the wall, the salt will never precipitate on the bottom as long as the concentration of the source brine is lower than $15 \mathrm{wt} \%$. This analysis explains our results that no salt precipitates on the bottom of the 3D cup evaporator with the brines of 10 and $15 \mathrm{wt} \%$ as source water in our experiment (Figure $6 \mathrm{f}$ and $\mathrm{g}$ ).

According to our calculation, when the brines of 20 and 25 wt $\%$ are employed, in order to control salt precipitation only in the wall part, the $\mathrm{ESP}_{\mathrm{w}}$ value has to be higher than $68 \%$ and $91 \%$, respectively. These values are not easy to achieve practically since the bottom part possesses much higher temperature than the wall part (Figure $6 r$ and ss). Herein we propose a different solution to solve the problem. The solution involves inserting a nonporous and transparent glass cup with a matching size into the SCS cup structure to entirely stop the water evaporation from the bottom part and the inner wall part without affecting the light absorbing and thus to effectively force $\mathrm{ESP}_{\mathrm{b}}$ to drop to $0 \%$. In other words, in this design, only the outer wall is used as a water evaporation surface, while the bottom and inner walls of the same cup are used exclusively for light absorption. This strategy completely eliminates water evaporation from the light absorbing surface, and therefore the adverse effect of the precipitation of $\mathrm{NaCl}$ on the light capture ability by the solar evaporator is totally eradicated.

To demonstrate, a 3D SCS cup with a $5.5 \mathrm{~cm}$ outer diameter and $10 \mathrm{~cm}$ height was employed, and a glass cup with a $5.2 \mathrm{~cm}$ outer diameter and $10 \mathrm{~cm}$ wall height was then placed inside the SCS cup. When it was used as a solar evaporator to treat 25 wt $\%$ brine, the initial water evaporation rate was $1.66 \mathrm{~kg} \mathrm{~m}^{2}$ $\mathrm{h}^{-1}$ (Figure $7 \mathrm{~b}$ ), which was close to that without a glass cup, indicating that the glass cup does not affect the energy efficiency. The evaporation rate gradually decreased to $1.33 \mathrm{~kg}$ $\mathrm{m}^{-2} \mathrm{~h}^{-1}$ after $10 \mathrm{~h}$. This evaporation rate decrease is presumably because the surface of the SCS material was slightly blocked by salt precipitation. While the evaporation rate remained relatively stable with some fluctuation within the range of 1.15 to $1.33 \mathrm{~kg} \mathrm{~m}^{-2} \mathrm{~h}^{-1}$ in the following hours (Figure $7 \mathrm{~b})$, the salt precipitation occurred expectedly only on the outer surface of the cup evaporator and the inner wall did not show any change after $48 \mathrm{~h}$ solar illumination (Figure $7 \mathrm{e}$ ). In the first $48 \mathrm{~h}, 148 \mathrm{~g}$ of water was evaporated away with an average evaporation rate of $1.30 \mathrm{~kg} \mathrm{~m}^{-2} \mathrm{~h}^{-1}$.

Very importantly, the precipitated salt crust was quite loose and composed by rough $\mathrm{NaCl}$ crystal balls with diameters in the range of $2-5 \mathrm{~mm}$ (Figure S12). The loose salt crust on the outer wall could be removed by a stainless steel scraper (Figure $7 \mathrm{f}$ ). The weight of the collected salt amounted to $39 \mathrm{~g}$ after 48 $\mathrm{h}$ of solar evaporation, which was $10 \mathrm{~g}$ less than the theoretical estimation, probably indicating some salt precipitation inside the pore space of the SCS membrane. This salt removal operation by physical scrapping was tested as the regeneration treatment for long-term operation then. As shown in Figure $7 \mathrm{~b}$, the $3 \mathrm{D}$ solar evaporator exhibited similar evaporation rates after it was regenerated.

When the simulated sunlight was turned off during operation, the evaporation rate dropped to $0.27 \mathrm{~kg} \mathrm{~m}^{-2} \mathrm{~h}^{-1}$ (Figure $7 \mathrm{~b}$ ). However, the salt crust on the outer wall surface did not show any noticeable change when the $3 \mathrm{D}$ evaporator was kept in the dark for $24 \mathrm{~h}$ (Figure $7 \mathrm{~g}$ and $\mathrm{h}$ ), indicating the redissolution of the salt crystals back into the source water was insignificant. In some literature reports, with a solar evaporator directly floating on top of seawater with 3.5 wt \% concentration, the precipitated salt would dissolve back to the bulk water in darkness. In our case, we believe the relatively high evaporation rate even in darkness $\left(0.27 \mathrm{~kg} \mathrm{~m}^{-2} \mathrm{~h}^{-1}\right)$ and the small concentration difference between the source water (25 wt \%) and the saturated solution inside the evaporator both slow down the salt dissolution. This special feature makes the $3 \mathrm{D}$ cup evaporator able to operate continuously during day and night without any special care.

When the simulated sunlight was turned on again, the evaporation rate of the device was back to $1.26 \mathrm{~kg} \mathrm{~m}^{-2} \mathrm{~h}^{-1}$. In the entire second cycle, from 48 to $120 \mathrm{~h}, 155 \mathrm{~g}$ of water was evaporated, and during which $51 \mathrm{~g}$ of salt was collected from the $3 \mathrm{D}$ solar evaporator, representing a near $100 \%$ salt recovery in this cycle. As discussed earlier, there was salt precipitation in the pore space inside the cup wall in the first cycle, but the high water evaporation rate in the second treatment cycle implies that the pore space inside the cup wall was not totally blocked by the precipitated salt, which can be clearly revealed in SEM images of the SCS membrane after $48 \mathrm{~h}$ continuous operation (Figure S14).

Our result clearly demonstrates that the formation of the salt crust layer on the outer surface of the wall does not affect the water evaporation rate during the long time operation. The salt crust layer always possesses a highly porous structure, which can be explained as follows. The salt crust layer is hydrophilic, and therefore the brine fills the inner pore space of the SCS membrane and the salt crust layer and forms a thin liquid film on the outer surface. The outer surface of the crust layer gives rise to a higher evaporation rate than its inner part, leading to a higher salt concentration and lower temperature in the outer part of the crust layer. Consequently, the salt always tends to precipitate in the outer part, instead of the interior. In addition, no water evaporation occurs in the SCS membrane after a relatively thick crust layer is formed on its outer surface. In this stage, the SCS membrane only acts as a transport pathway. Since the brine is not saturated, the $\mathrm{NaCl}$ crystal formed in the early stage may redissolve in the brine. This mechanism can explain the occasional falling of the salt crystal from the wall during long time operation, as shown in Figure S15. The highly porous structure of the salt crust layer and the self-cleaning behavior of the SCS membrane ensure the 3D cup solar evaporator has potential for continuous operation toward highly saline brine treatment.

ZLD Solar Desalination in a Lab-Made Solar Still. The 3D solar evaporator fabricated in this work can be used as a solar brine crystallizer operating in open air without collecting water condensate. In this configuration, it converts high concentration brines coming from conventional desalination plants to solid salts, achieving a ZLD desalination goal for the desalination plants. On the other hand, it can also be used within solar stills to produce clean water from brines by collecting the generated water vapor via condensation. To this end, we employed a lab-made solar still (Figure S17) and tested the performance of the 3D solar evaporator with $5.5 \mathrm{~cm}$ diameter and $10 \mathrm{~cm}$ height (i.e., with a glass cup inside the SCS cup) under one sun illumination. When the salt concentration of the source water is $15 \mathrm{wt} \%$, the weight of the source brine decreased by $36.8 \mathrm{~g}$ after $24 \mathrm{~h}$, and $26.9 \mathrm{~g}$ of clean water was collected, equivalent to a brine treatment rate 
of $0.64 \mathrm{~kg} \mathrm{~m}^{-2} \mathrm{~h}^{-1}$ and a clean water production rate of $0.47 \mathrm{~kg}$ $\mathrm{m}^{-2} \mathrm{~h}^{-1}$. When the concentration of the brine increased to 25 wt $\%$, a brine treatment rate of $0.66 \mathrm{~kg} \mathrm{~m}^{-2} \mathrm{~h}^{-1}$ and a clean water production rate of $0.43 \mathrm{~kg} \mathrm{~m}^{-2} \mathrm{~h}^{-1}$ were obtained under the same conditions. As expected, within the solar still, all of the salts precipitated exclusively on the outer wall of the cup (Figure S16). As a matter of fact, the clean water production rate within the solar still was slightly underestimated because some water droplets were still on the inner walls of the solar still and could not be collected for the measurement purpose. Based on the weight decrease of the source brines, the clean water production rates by our $3 \mathrm{D}$ cup in the solar still system for 15 wt \% brine and 25 wt \% brine would be 0.55 and $0.50 \mathrm{~kg}$ $\mathrm{m}^{-2} \mathrm{~h}^{-1}$, respectively. A clean water productivity of $>3 \mathrm{~kg} \mathrm{~m}^{-2}$ per day from concentrated brine can be expected for this simple device, which is even higher than some carefully designed commercial solar stills when they are operated with lake water and seawater. ${ }^{31,59,60}$ The comparison demonstrates the advantage of our solar evaporator design in direct desalination of highly concentrated brines. When the solar still is operated with extremely high concentration brine (25 wt $\%)$, its clean water production rate is only slightly lower than that with 15 wt \% brine, but more brine (37.8 g for $25 \mathrm{wt} \%$ brine) is converted to solid salt than the latter ( $36.8 \mathrm{~g}$ for $15 \%$ brine). This is to say that brine treatment capacity is higher for more concentrated brine with our technology. The above result demonstrated that this $3 \mathrm{D}$ cup structure can be used as a brine crystallizer in open air for highly concentrated brine treatment and as a solar evaporator in a closed chamber in a solar still for direct ZLD desalination. It only uses green energy and common cheap materials, and no high pressure or vacuum operation is involved, which are otherwise required in a conventional ZLD system. These features make the 3D solar evaporator a very promising device in a ZLD desalination system.

\section{ASSOCIATED CONTENT}

\section{S Supporting Information}

The Supporting Information is available free of charge on the ACS Publications website at DOI: 10.1021/acs.est.8b03300.

Expermental section (PDF)

\section{AUTHOR INFORMATION}

\section{Corresponding Author}

*E-mail: peng.wang@kaust.edu.sa.

\section{ORCID $\odot$}

Renyuan Li: 0000-0003-1943-9403

Yong Jin: 0000-0002-4929-4623

Seunghyun Hong: 0000-0001-5810-9250

Peng Wang: 0000-0003-0856-0865

\section{Notes}

The authors declare no competing financial interest.

\section{ACKNOWLEDGMENTS}

This work was supported by the King Abdullah University of Science and Technology (KAUST) Center Competitive Fund (CCF) awarded to the Water Desalination and Reuse Center (WDRC).

\section{REFERENCES}

(1) Pinto, F. S.; Marques, R. C. Desalination projects economic feasibility: A standardization of cost determinants. Renewable Sustainable Energy Rev. 2017, 78, 904-915.

(2) Gude, V. G. Desalination and sustainability - An appraisal and current perspective. Water Res. 2016, 89, 87-106.

(3) Ziolkowska, J. R. Desalination leaders in the global market current trends and future perspectives. Water Sci. Technol:: Water Supply 2016, 16, 563-578.

(4) Gao, L.; Yoshikawa, S.; Iseri, Y.; Fujimori, S.; Kanae, S. An economic assessment of the global potential for seawater desalination to 2050. Water 2017, 9, 763 .

(5) Ahmad, N.; Baddour, R. E. A review of sources, effects, disposal methods, and regulations of brine into marine environments. Ocean Coast. Manag. 2014, 87, 1-7.

(6) Ahmed, M.; Shayya, W. H.; Hoey, D.; Al-Handaly, J. Brine disposal from reverse osmosis desalination plants in Oman and the United Arab Emirates. Desalination 2001, 133, 135-147.

(7) Afrasiabi, N.; Shahbazali, E. RO brine treatment and disposal methods. Desalin. Water Treat. 2011, 35, 39-53.

(8) Pramanik, B. K.; Shu, L.; Jegatheesan, V. A review of the management and treatment of brine solutions. Environ. Sci. Water Res. Technol. 2017, 3, 625-658.

(9) Warner, N. R.; Christie, C. A.; Jackson, R. B.; Vengosh, A. Impacts of shale gas wastewater disposal on water quality in western Pennsylvania. Environ. Sci. Technol. 2013, 47, 11849-11857.

(10) Tong, T. Z.; Elimelech, M. The Global Rise of Zero Liquid Discharge for Wastewater Management: Drivers, Technologies, and Future Directions. Environ. Sci. Technol. 2016, 50, 6846-6855.

(11) Gacia, E.; Invers, O.; Manzanera, M.; Ballesteros, E.; Romero, J. Impact of the brine from a desalination plant on a shallow seagrass (Posidonia oceanica) meadow. Estuarine, Coastal Shelf Sci. 2007, 72, 579-590.

(12) Mohamed, A.; Maraqa, M.; Al Handhaly, J. Impact of land disposal of reject brine from desalination plants on soil and groundwater. Desalination 2005, 182, 411-433.

(13) Del Bene, J.; Jirka, G.; Largier, J. Ocean brine disposal. Desalination 1994, 97, 365-372.

(14) Sanchez-Lizaso, J. L.; Romero, J.; Ruiz, J.; Gacia, E.; Buceta, J. L.; Invers, O.; Torquemada, Y. F.; Mas, J.; Ruiz-Mateo, A.; Manzanera, M. Salinity tolerance of the Mediterranean seagrass Posidonia oceanica: recommendations to minimize the impact of brine discharges from desalination plants. Desalination 2008, 221, 602-607.

(15) Morillo, J.; Usero, J.; Rosado, D.; El Bakouri, H.; Riaza, A.; Bernaola, F.-J. Comparative study of brine management technologies for desalination plants. Desalination 2014, 336, 32-49.

(16) Subramani, A.; Jacangelo, J. G. Treatment technologies for reverse osmosis concentrate volume minimization: A review. Sep. Purif. Technol. 2014, 122, 472-489.

(17) Pérez-González, A.; Urtiaga, A. M.; Ibáñez, R.; Ortiz, I. State of the art and review on the treatment technologies of water reverse osmosis concentrates. Water Res. 2012, 46, 267-283.

(18) Chen, X.; Yip, N. Y. Unlocking high-salinity desalination with cascading osmotically mediated reverse osmosis: energy and operating pressure analysis. Environ. Sci. Technol. 2018, 52, 2242-2250.

(19) Tiwari, G. N.; Singh, H. N.; Tripathi, R. Present status of solar distillation. Sol. Energy 2003, 75, 367-373.

(20) Li, C. N.; Goswami, Y.; Stefanakos, E. Solar assisted sea water desalination: A review. Renewable Sustainable Energy Rev. 2013, 19, $136-163$.

(21) Zhang, Q.; Xu, W.; Wang, X. Carbon nanocomposites with high photothermal conversion efficiency. Sci. Chin. Mater. 2018, 61, 905-914.

(22) Liu, G.; Xu, J.; Wang, K. Solar water evaporation by black photothermal sheets. Nano Energy 2017, 41, 269-284.

(23) Deng, Z.; Zhou, J.; Miao, L.; Liu, C.; Peng, Y.; Sun, L.; Tanemura, $\mathrm{S}$. The emergence of solar thermal utilization: solar-driven steam generation. J. Mater. Chem. A 2017, 5, 7691-7709. 
(24) Zeng, Y.; Yao, J.; Horri, B. A.; Wang, K.; Wu, Y.; Li, D.; Wang, $\mathrm{H}$. Solar evaporation enhancement using floating light-absorbing magnetic particles. Energy Environ. Sci. 2011, 4, 4074-4078.

(25) Ghasemi, H.; Ni, G.; Marconnet, A. M.; Loomis, J.; Yerci, S.; Miljkovic, N.; Chen, G. Solar steam generation by heat localization. Nat. Commun. 2014, 5, 4449.

(26) Bae, K.; Kang, G.; Cho, S. K.; Park, W.; Kim, K.; Padilla, W. J. Flexible thin-film black gold membranes with ultrabroadband plasmonic nanofocusing for efficient solar vapour generation. Nat. Commun. 2015, 6, 10103.

(27) Li, X.; Xu, W.; Tang, M.; Zhou, L.; Zhu, B.; Zhu, S.; Zhu, J. Graphene oxide-based efficient and scalable solar desalination under one sun with a confined 2D water path. Proc. Natl. Acad. Sci. U. S. A. 2016, 113, 13953-13958.

(28) Zhou, L.; Tan, Y.; Ji, D.; Zhu, B.; Zhang, P.; Xu, J.; Gan, Q.; Yu, Z.; Zhu, J. Self-assembly of highly efficient, broadband plasmonic absorbers for solar steam generation. Sci. Adv. 2016, 2, e1501227.

(29) Ni, G.; Li, G.; Boriskina, S. V.; Li, H. X.; Yang, W. L.; Zhang, T. J.; Chen, G. Steam generation under one sun enabled by a floating structure with thermal concentration. Nat. Energy 2016, 1, 16126.

(30) Liu, Y.; Yu, S.; Feng, R.; Bernard, A.; Liu, Y.; Zhang, Y.; Duan, H.; Shang, W.; Tao, P.; Song, C.; Deng, T. A bioinspired, reusable, paper-based system for high-performance large-scale evaporation. Adv. Mater. 2015, 27, 2768-2774.

(31) Liu, Z.; Song, H.; Ji, D.; Li, C.; Cheney, A.; Liu, Y.; Zhang, N.; Zeng, X.; Chen, B.; Gao, J.; Li, Y.; Liu, X.; Aga, D.; Jiang, S.; Yu, Z.; Gan, Q. Extremely cost-effective and efficient solar vapor generation under nonconcentrated illumination using thermally isolated black paper. Global Challenges 2017, 1, 1600003.

(32) Zhou, L.; Tan, Y. L.; Wang, J. Y.; Xu, W. C.; Yuan, Y.; Cai, W. S.; Zhu, S. N.; Zhu, J. 3D self-assembly of aluminium nanoparticles for plasmon-enhanced solar desalination. Nat. Photonics 2016, 10, 393398.

(33) Wang, Y.; Wang, C.; Song, X.; Huang, M.; Kumar, S.; Shaukat, S. F.; Jiang, H. Improved light-harvesting and thermal management for efficient solar-driven water evaporation using 3D photothermal cone. J. Mater. Chem. A 2018, 6, 9874-9881.

(34) Shi, Y.; Li, R.; Jin, Y.; Zhuo, S.; Shi, L.; Chang, J.; Hong, S.; Ng, K.-C.; Wang, P. A 3D photothermal structure toward improved energy efficiency in solar steam generation. Joule 2018, 2, 1171-1186.

(35) Li, X.; Li, J.; Lu, J.; Xu, N.; Chen, C.; Min, X.; Zhu, B.; Li, H.; Zhou, L.; Zhu, S.; Zhang, T.; Zhu, J. Enhancement of interfacial solar vapor generation by environmental energy. Joule 2018, 2, 1331-1338.

(36) Jia, C.; Li, Y.; Yang, Z.; Chen, G.; Yao, Y.; Jiang, F.; Kuang, Y.; Pastel, G.; Xie, H.; Yang, B. Rich mesostructures derived from natural woods for solar steam generation. Joule 2017, 1, 588-599.

(37) Yang, P.; Liu, K.; Chen, Q.; Li, J.; Duan, J.; Xue, G.; Xu, Z.; Xie, W.; Zhou, J. Solar-driven simultaneous steam production and electricity generation from salinity. Energy Environ. Sci. 2017, 10, 1923-1927.

(38) Li, X.; Lin, R.; Ni, G.; Xu, N.; Hu, X.; Zhu, B.; Lv, G.; Li, J.; $\mathrm{Zhu}, \mathrm{S}$.; Zhu, J. Three-dimensional artificial transpiration for efficient solar waste-water treatment. Natl. Sci. Rev. 2018, 5, 70-77.

(39) Zhang, P.; Li, J.; Lv, L.; Zhao, Y.; Qu, L. Vertically aligned graphene sheets membrane for highly efficient solar thermal generation of clean water. ACS Nano 2017, 11, 5087-5093.

(40) Ito, Y.; Tanabe, Y.; Han, J.; Fujita, T.; Tanigaki, K.; Chen, M. Multifunctional porous graphene for high-efficiency steam generation by heat localization. Adv. Mater. 2015, 27, 4302-4307.

(41) Jiang, Q.; Tian, L.; Liu, K. K.; Tadepalli, S.; Raliya, R.; Biswas, P.; Naik, R. R.; Singamaneni, S. Bilayered biofoam for highly efficient solar steam generation. Adv. Mater. 2016, 28, 9400-9407.

(42) Zhao, F.; Zhou, X.; Shi, Y.; Qian, X.; Alexander, M.; Zhao, X.; Mendez, S.; Yang, R.; Qu, L.; Yu, G. Highly efficient solar vapour generation via hierarchically nanostructured gels. Nat. Nanotechnol. 2018, 13, 489-495.

(43) Finnerty, C.; Zhang, L.; Sedlak, D. L.; Nelson, K. L.; Mi, B. Synthetic graphene oxide leaf for solar desalination with zero liquid discharge. Environ. Sci. Technol. 2017, 51, 11701-11709.
(44) Ni, G.; Zandavi, S. H.; Javid, S. M.; Boriskina, S. V.; Cooper, T. A.; Chen, G. A salt-rejecting floating solar still for low-cost desalination. Energy Environ. Sci. 2018, 11, 1510-1519.

(45) Zhu, M.; Li, Y.; Chen, G.; Jiang, F.; Yang, Z.; Luo, X.; Wang, Y.; Lacey, S. D.; Dai, J.; Wang, C. Tree-inspired design for high-efficiency water extraction. Adv. Mater. 2017, 29, 1704107.

(46) Xu, W.; Hu, X.; Zhuang, S.; Wang, Y.; Li, X.; Zhou, L.; Zhu, S.; $\mathrm{Zhu}, \mathrm{J}$. Flexible and salt resistant Janus absorbers by electrospinning for stable and efficient solar desalination. Adv. Energy Mater. 2018, 8, 1702884.

(47) Shi, Y.; Li, R.; Shi, L.; Ahmed, E.; Jin, Y.; Wang, P. A robust $\mathrm{CuCr}_{2} \mathrm{O}_{4} / \mathrm{SiO}_{2}$ composite photothermal material with underwater black property and extremely high thermal stability for solar-driven water evaporation. Adv. Sust. Sys. 2018, 2, 1700145.

(48) Lekner, J.; Dorf, M. C. Why some things are darker when wet. Appl. Opt. 1988, 27, 1278-1280.

(49) Twomey, S. A.; Bohren, C. F.; Mergenthaler, J. L. Reflectance and albedo differences between wet and dry surfaces. Appl. Opt. 1986, 25, 431-437.

(50) Cai, J. G.; Qi, L. M. Recent advances in antireflective surfaces based on nanostructure arrays. Mater. Horiz. 2015, 2, 37-53.

(51) Khashan, M.; Nassif, A. Dispersion of the optical constants of quartz and polymethyl methacrylate glasses in a wide spectral range: 0.2-3 $\mu \mathrm{m}$. Opt. Commun. 2001, 188, 129-139.

(52) Kedenburg, S.; Vieweg, M.; Gissibl, T.; Giessen, H. Linear refractive index and absorption measurements of nonlinear optical liquids in the visible and near-infrared spectral region. Opt. Mater. Express 2012, 2, 1588-1611.

(53) Stagg, B.; Charalampopoulos, T. Refractive indices of pyrolytic graphite, amorphous carbon, and flame soot in the temperature range 25 to 600C. Combust. Flame 1993, 94, 381-396.

(54) Raut, H. K.; Ganesh, V. A.; Nair, A. S.; Ramakrishna, S. Antireflective coatings: A critical, in-depth review. Energy Environ. Sci. 2011, 4, 3779-3804.

(55) Clarke, E. C. W.; Glew, D. N. Evaluation of the thermodynamic functions for aqueous sodium chloride from equilibrium and calorimetric measurements below 154 C. J. Phys. Chem. Ref. Data 1985, 14, 489-610.

(56) Pitzer, K. S.; Peiper, J. C.; Busey, R. Thermodynamic properties of aqueous sodium chloride solutions. J. Phys. Chem. Ref. Data 1984, $13,1-102$.

(57) Collins, J. Change in the infra-red absorption spectrum of water with temperature. Phys. Rev. 1925, 26, 771-779.

(58) Penman, H. L. Natural evaporation from open water, bare soil and grass. Proc. R. Soc. London, Ser. A 1948, 193, 120-145.

(59) Sivakumar, V.; Sundaram, E. G. Improvement techniques of solar still efficiency: A review. Renewable Sustainable Energy Rev. 2013, $28,246-264$

(60) Durkaieswaran, P.; Murugavel, K. K. Various special designs of single basin passive solar still-A review. Renewable Sustainable Energy Rev. 2015, 49, 1048-1060. 